\title{
In-process measurement of urban energy-oxygen-pollution for the main residential building areas in Timisoara
}

\author{
Vasile Dogaru ${ }^{1, *}$ \\ ${ }^{1}$ West University of Timisoara, Nicholas Georgescu-Roegen Interdisciplinary Platform, 300223 Vasile Parvan 4A/704C, Romania
}

\begin{abstract}
The development of cities is below the target in reducing pollution and high population density. The environmental agency formulated the rules for the construction of spatial area-based balances of energy use-oxygen production-pollution for the new Building Code of Timisoara. Studies for households or traffic typically evaluate separately energy, oxygen production or pollution. In this research, we have developed a flow-funds model for conterminous residential building processes with spatial-temporal borders. We are modeling the integrated processes for energy-oxygen-pollution in 14 urban zones for households-buildings with segmentation of partial processes for energy-pollution and separately for oxygen flows. The segmentation is based on modeling of 338 streets at nano-levels as street segments. We have found a new solution for the boundaries in place of the 73 Territorial References Units in the in force Building Code. We made the distinction between area-point and in-process measurement. The modeling revealed that national energy-pollution balances did not integrate oxygen urban production which overestimates the $\mathrm{CO} 2$ reported figures. The daily intensity of carbon sequestration in the warm season for 14 zones in Timisoara varies between 0.21-0.70 grams per meter squared for residential areas. The different carbon sequestration intensity justifies differentiated measures to reduce the pollution in residential areas.
\end{abstract}

\section{Introduction}

Urban living areas occupy $0.2 \%$ of the world's surface [1], and the related pollution is about $50-60 \%$. The energy use (E) and pollution (P) on an urban hectare can be considered, under average conditions, to be $250-$ 300 times higher than outside of the cities. So the interest to integrate some studies of the energy, oxygen production (O2) and pollution (EO2P) of urban processes appears to be justified [2-5]. In the last decade, the study has been more focused on the small urban areas, to be further called micro-zones and nano-zones, due to high pollution and population density. Starting at the valuation of urban processes, some researchers introduced, over half a century ago, in the absence of proper management of urban challenges, the hypothesis of de-urbanization in the future [6]. Today, next to the population and pollution density, these challenges included the frequent increase of some extreme climatic phenomena such as heat islands (waves) and storms.

Timisoara has managed, as region-capital city, over $60 \%$ of the activities of the most dynamic below middle income region of the European Union, from more than 1320 NUTS 3 regions over the 2000-2010 period. This dynamic has generated an increase in energy use and higher pollution [7]. Timisoara's in force local planning documents, from the last 17 years and ongoing, set the building requirements through the Building Code [8]. This code is called the General Urban Plan (GUP) in Romanian legislation. The new ongoing GUP for
Timisoara [9] is built under the umbrella of the NUTS 3 424 Development Strategy 2014-2020 and Vision 2050 Timis.

The European targets for pollution reduction, such as the 20-20-20 target and Directive 31/ EC/2010 for nearly Zero Energy Buildings especially, are assumed locally [7]. Extreme weather events such as storms and heat waves, that have been more and more frequent in Romania, add to the new decoupling requirements [10]. The storm on the $14^{\text {th }}$ of September 2017, in Timisoara, measuring wind speeds of over $122 \mathrm{~km} / \mathrm{h}$, generated damages and raised significant questions for the population. It was the first major storm in an urban area in Romania. The chances of recurrence raise the issue of urban design related to the density of population and the intensity of energy used for buildings and traffic.

Some formal elements that do not serve urban plan evaluation appear in the drafting of the GUP [9]. Board layout design, without being accompanied by proper measurement, seems to be a direction of formalism maintained in urbanism after 1990 [11]. Two major inconveniences are currently hampering the integrated assessment of E-P processes in Romania [9]: removing some surfaces from the spatial assessment, including the border streets, and the lack of a unique classification in assessing urban characteristics for every territorial reference unit (TRU).

Regarding the in force GUP [12], the segmentation of Timisoara's urban area in 73 TRUs is made by delimiting them by 109 border-streets. In this GUP,

Corresponding author: vasile.dogaru@e-uvt.ro 
every TRU has the specific requirements. It is not clear at which of the two TRUs, that are bounded by the street-border under discussion, belongs to the surface of this street. Therefore, the street surface, starting with the width, appears to be missed from the analytical point of view for the metric analysis which uses the proper spatial classification. In Timisoara, an area of several hectares corresponding to the border-streets is considered from the analytical point of view, as outside the surfaces of the 73 existing TRUs. In fact, these crossborder streets are spatially located between, not inside of the TRUs. Based on Roegenian analytics [6], each street should have been included into a single TRU to analyze the impact of the traffic and households $(\mathrm{HH})$ energy consumption. Paradoxically, the spatial classification was abandoned until this design phase in the new GUP [9]. Other cities (Barcelona, London) have the definitive divisions, used to assess the urban characteristics.

Nicholas Georgescu-Roegen [6] proposes to build a flow-funds model in two evaluation phases, metric and literal. Therefore it is possible to solve these two inconveniences using some analytical requirements related to the fixing of temporal and spatial borders. Into the ongoing GUP dossier-documents we will avoid the missing or overlapping of some urban zones when the urban characteristics are assessed. So, by observing and measuring these characteristics, the valuation will take into consideration all the micro-zone from every zone or TRU.

Two decades ago the green inventory started for Timisoara and was completed on significant areas (over $30-50 \%$ ) of the city [13]. In supporting the need for increased oxygen production in the green areas in the documentation of the new GUP, it was mentioned the daily green space productivity by 20 grams of oxygen per cubic meter tree crown was mentioned, referred as Leaf Area Density (LAD) by Janjäll [14]. In some countries, the urban trees inventory was modeled using tree samples or area samples [2,15]. The urban $\mathrm{O} 2$ production contributes to the partial sequestration of carbon [3,5]. Urban $\mathrm{O} 2$ production is not found as a figure in the official pollution statistics [16]. Therefore, the national (aggregate) pollution measurement, under some international Convention [17], appears to not be taken into account of carbon sequestration in urban areas. For conterminous areas, the flows of $\mathrm{O} 2$ and $\mathrm{CO} 2$ are not modeled separately and are to be integrated afterwards $[3,4]$.

The green space generates oxygen production through trees, which have the possibility of a dominant, vertical (unlimited) expansion. On the other hand, the grass surface has the possibility of limited, horizontal expansion [14]. In Romanian legislation there is not a clear distinction between the green grassland space and the unconstructed space, considered as non-artificial area. Thus, the green grassland space is sometimes overlapped and therefore considered equal to the unconstructed space. The trees inventory allows us the calculation of benefits regarding ecosystem services and urban wellbeing related to the decrease of $\mathrm{CO} 2$ pollution. The presence of urban forests in 10-megacities of the world, covering about $2 \%$ of the world's population, has beneficial effects [15].

The assessment of urban oxygen production and pollution in urban areas (cities) or some US states is made by using the carbon sequestration process. Hutyra et all [5] identify disparities between sequestration capacity in different urban areas from 3.14 to $14.1 \mathrm{~kg} \mathrm{C}$ square meters (cover). Certain authors indirectly assess the production of oxygen and the sequestration of pollutants by tree types and their proximity to the main pollution sources, especially the traffic [14].

For some cities the urban consumption of fuel is assessed to achieve the neutral $\mathrm{CO} 2[18,19]$. A similar gradual $\mathrm{CO} 2$ reduction is targeted in Timisoara [7] because the pressure (possibility) on tree cover extension is limited [13]. Additionally, growing urban forests may have negative effects on winter building heating [15]. In some European cities (London, Rotterdam), the pollution is recorded for every building of the main streets. Managing the urban E-P flows may require some prohibited solutions. In some cities, traffic blocking measures were tested [8].

The current research is aimed at providing a framework for the partial segmentation of Timisoara, to modeling the energy, pollution and $\mathrm{O} 2$ border flows for the 14 residential areas. The described framework can be used by other researchers to model the TRU EO2P flows for the local decision makers to achieve the annual environmental balances required by the Environment Ministry (local agency) [20]. Both O2 internal production and the border flows of photosynthesis process will be modeled for the residential micro-areas.

\section{Methods}

The analytical framework has 2 stages: segmentation of Timisoara in 14 continuous areas, as partially Roegenian processes and their analysis as experimentareas and for the future TRU-areas within the new GUP. TRU are not permanently determined and can be modified in Romanian legislation. In the second stage the metric follows the photosynthesis cycle: energy use $\rightarrow$ pollution $\rightarrow \mathrm{O} 2$ production $\rightarrow \mathrm{CO} 2$ neutral.

The model created through the framework follows: $a$. testing of a model for the requested EO2P balances through the Local Environment Permit 1/2017 [20]; b. nearing towards the $\mathrm{CO} 2$ neutral solution for Timisoara, by using the proposed model; the support of the city's development frame is assured in accordance with the national and European requirements, including some elements that seek the decoupling of resources. The $\mathrm{CO} 2$ neutral solution is permanently observed as a reference point, in relation with the $\mathrm{CO} 2$ amount. Finally the EO2P metrics will support the public decisions according to the frame created by the new GUP.

The 14 urban residential areas are described using the flow-funds model by funds (infrastructure) - buildings, trees, heating-cooling devices - and the urban border EO2P flows. Agents, funds, and flows can be assigned (as information and process) to a street-postal address. 
The description of urban and $\mathrm{HH}$ processes relies upon information from local, national and European databases and from cited literature. The data from local processes were calibrated with data from the national level (NIS, 2018). We used data from [7], RNAEP Timis Branch database and national database on fuel consumption and pollution from traffic and $\mathrm{HH}$. Initial data on green inventory $(\mathrm{O} 2)$ were used [13].

Splitting the whole city into conterminous TRUs is an analytical condition and it is necessary for a dynamic city. The spatial borders segment of the 14 zones is selected by an analytical surface without widthdimension following the model requirement [6]. Segmentation of urban land areas at different levels was done through spatial analytical border found between the two adjacent and conterminous land surfaces, located on the two adjacent streets. The issue of the border-streets has an innovative solution for the new ongoing GUP. The 14 zones are considered continuous spatial processes and the input-output flows are recorded for every process at the spatial and temporal borders. The temporal borders are established for one warm season day (24 hours) during 2016. The metrics can be calculated for the whole year by using the appropriate measurements.

The 14 areas were selected from the city of Timisoara. The areas ranged from 13.8 ha to 35.8 ha (table 2). The coding of the 14 zones is $\mathrm{Z1}, \mathrm{Z2}, \ldots, \mathrm{Z} 14$. After the temporal and spatial boundaries of the 14 zones as pRP have been set, the border flows and the funds of these processes have been modeled. The 14 processareas in Timisoara cover $28.62 \%$ of the entire population of Timisoara. Each of the 14 areas was divided into two partial processes considered micro-zones: for buildings/ households areas and for non-artificial land areas, as green areas. The residential micro-zone process working for heating/cooling processes and the green micro-zone generates $\mathrm{O} 2$ production by carbon sequestration, starting to $\mathrm{CO} 2$ flows received from the residential micro-zones. All partial micro-processes are conterminous and can be spatial joined. The metrics for these micro-zones are aggregated at zone level. The spatial street areas assigned to these 14 residential areas are not included as surface and EO2P flows into the residential building processes. The requirements to build yearly EO2P environmental balances for these 14 areas were established by Local Environmental Permit No. 1/ 2017 [20]. The temporal borders are established for one day (24 hours) in the warm season during 2016. The metrics can be calculated for the whole year using the appropriate measurements.

The initial data was modeled for street segments using the formula system (1) - (5). The primary requirement of the developed Roegenian model is to describe the process using only border flows and excluding the aggregation of internal flows - like $\mathrm{O} 2$ production at the zone level - found inside of the zoneprocess. The border energy flows for residential building (for heating-cooling) and oxygen production were analyzed. $\mathrm{CO} 2$ flows are considered waste and border flows for residential areas. $\mathrm{CO} 2$ is partially recoverable by the green micro-zones with $\mathrm{O} 2$ production. $\mathrm{O} 2$ production transforms this $\mathrm{CO} 2$ input flow for green area into a raw material for production. The recipe for manufacturing inside each process, as a relationship between output and input flows, is partially described by the formula system. The recipe is also partially described and explained by the intensity of EO2P flows, also based on the funds structure: People (HH), Drivers, Cars, Trees. The system of formulas is described in the next paragraphs.

Daily energy use for residential building/HH for zone $i$, is given by formula (1)

$E_{\mathrm{i}}=\sum_{\mathrm{j}} \sum_{\mathrm{k}}\left(P_{\mathrm{ij}} * C s a_{\mathrm{ijk}} *\right.$ enuseHH/msq $)$

The modeling of energy can be made according to the level of joining the urban building process at any intermediary level for micro-zone (street) $j$. Daily energy use per capita is given by formula (2)

enuseHH/msq $=\sum_{1}\left(E m_{1} /(N d w s * N p u H H * p k W h)\right.$

Calculation for building was modelled for gas. Electricity and other fuels are considered indirect energy or have a small contribution in the noticed micro-areas. Coefficient of spatial allocation for people on the street segment $k$, living on street $j$ is given by formula (3)

$C s a_{\mathrm{ijk}}=\operatorname{RAD}\left[\left(N p s s_{\mathrm{ijk}} * L s s_{\mathrm{ijk})} /\left(N p s_{\mathrm{ij}} * L s_{\mathrm{ij}}\right)\right]\right.$

The daily $\mathrm{CO} 2$ pollution for building area for zone i, is measured by formula (4)

Pco $2 H H d_{\mathrm{i}}=\sum_{\mathrm{j}} \sum_{\mathrm{k}}\left(P_{\mathrm{ij}} *\right.$ Csa $a_{\mathrm{ijk}} *$ enuseHH/msq $\left.* f \operatorname{co} 2 H H\right)(4)$

The $\mathrm{O} 2$ production for building/HH zone $i$ for one day in the warm season, inside of the green micro-zone $i$ (non artificial land area), is calculated by formula (5)

$\operatorname{PrO}_{2 H} H_{\mathrm{i}}=\sum_{\mathrm{j}} \sum_{\mathrm{k}}\left(\mathrm{SLAI} t_{\mathrm{ijk}}+S L A I g_{\mathrm{ijk}}\right) * p O 2 / 150$

\section{Calculation and results}

The statistics for the main characteristics for $\mathrm{O} 2$ production, $\mathrm{CO} 2$ pollution, intensity of unsequestration and sequestration carbon for residential zone is shown in table 1 .

Table 1 Main statistics residential building processes, warm season day, 14 zones, Timisoara, 2016

\begin{tabular}{|l|l|r|r|r|}
\hline Indicator & UM & \multicolumn{1}{l|}{ Total } & \multicolumn{1}{l|}{ min } & \multicolumn{1}{l|}{ max } \\
\hline $\begin{array}{l}\text { Surface zone } \\
\text { areas }\end{array}$ & ha & 998.8 & 13.8 & 145.9 \\
\hline $\begin{array}{l}\text { Surface HH } \\
\text { areas }\end{array}$ & ha & 686.7 & 4.1 & 110.9 \\
\hline People & 0000 no & 9.54 & 0.06 & 1.82 \\
\hline Prod O2 & tons & 0.94 & 0.002 & 0.13 \\
\hline CO2 pollution & tons & 13.96 & 0.09 & 2.66 \\
\hline grCseq/msq & $\begin{array}{l}\text { grams } \\
\text { C/msq }\end{array}$ & 0.51 & 0.21 & 0.70 \\
\hline grCunseq/msq & $\begin{array}{l}\text { grams } \\
\text { C/msq }\end{array}$ & 5.03 & 0.85 & 10.86 \\
\hline
\end{tabular}


The population of 9.54 thousands people is $28.62 \%$ of the entire population of Timisoara. The zones' surface is $7.7 \%$ of the entire land area of Timisoara and only $5.3 \%$ for the total residential building areas (table2).

Table 2 The surface (ha), $\mathrm{CO} 2$ and $\mathrm{O} 2$ production (grams), 2016, dayly

\begin{tabular}{|l|c|c|c|c|l|}
\hline Zone & $\begin{array}{l}\text { Surface } \\
\text { total }\end{array}$ & $\begin{array}{l}\text { HH } \\
\text { surface }\end{array}$ & People & O2 & CO2 \\
\hline$Z 01$ & $8.8 \mathrm{E}+05$ & $5.4 \mathrm{E}+05$ & $1.6 \mathrm{E}+04$ & $9.0 \mathrm{E}+05$ & $2.3 \mathrm{E}+07$ \\
\hline$Z 02$ & $8.2 \mathrm{E}+05$ & $6.7 \mathrm{E}+05$ & $1.0 \mathrm{E}+04$ & $1.1 \mathrm{E}+06$ & $1.5 \mathrm{E}+07$ \\
\hline$Z 03$ & $6.4 \mathrm{E}+05$ & $3.8 \mathrm{E}+05$ & $7.5 \mathrm{E}+03$ & $4.3 \mathrm{E}+05$ & $1.1 \mathrm{E}+07$ \\
\hline$Z 04$ & $3.6 \mathrm{E}+05$ & $2.1 \mathrm{E}+05$ & $6.0 \mathrm{E}+03$ & $2.9 \mathrm{E}+05$ & $8.7 \mathrm{E}+06$ \\
\hline$Z 05$ & $6.6 \mathrm{E}+05$ & $5.2 \mathrm{E}+05$ & $3.7 \mathrm{E}+03$ & $8.2 \mathrm{E}+05$ & $5.4 \mathrm{E}+06$ \\
\hline$Z 06$ & $3.2 \mathrm{E}+05$ & $1.8 \mathrm{E}+05$ & $3.6 \mathrm{E}+03$ & $2.6 \mathrm{E}+05$ & $5.3 \mathrm{E}+06$ \\
\hline$Z 07$ & $7.2 \mathrm{E}+05$ & $4.4 \mathrm{E}+05$ & $5.0 \mathrm{E}+03$ & $5.7 \mathrm{E}+05$ & $7.3 \mathrm{E}+06$ \\
\hline$Z 08$ & $1.5 \mathrm{E}+06$ & $9.8 \mathrm{E}+05$ & $1.8 \mathrm{E}+04$ & $9.9 \mathrm{E}+05$ & $2.7 \mathrm{E}+07$ \\
\hline$Z 09$ & $4.2 \mathrm{E}+05$ & $2.3 \mathrm{E}+05$ & $3.2 \mathrm{E}+03$ & $2.8 \mathrm{E}+05$ & $4.6 \mathrm{E}+06$ \\
\hline$Z 10$ & $1.0 \mathrm{E}+06$ & $7.9 \mathrm{E}+05$ & $6.9 \mathrm{E}+03$ & $1.0 \mathrm{E}+06$ & $1.0 \mathrm{E}+07$ \\
\hline$Z 11$ & $4.5 \mathrm{E}+05$ & $2.1 \mathrm{E}+05$ & $3.1 \mathrm{E}+03$ & $3.3 \mathrm{E}+05$ & $4.5 \mathrm{E}+06$ \\
\hline$Z 12$ & $7.8 \mathrm{E}+05$ & $5.7 \mathrm{E}+05$ & $8.3 \mathrm{E}+03$ & $1.1 \mathrm{E}+06$ & $1.2 \mathrm{E}+07$ \\
\hline$Z 13$ & $1.4 \mathrm{E}+05$ & $4.1 \mathrm{E}+04$ & $6.3 \mathrm{E}+02$ & $2.3 \mathrm{E}+04$ & $9.2 \mathrm{E}+05$ \\
\hline$Z 14$ & $1.3 \mathrm{E}+06$ & $1.1 \mathrm{E}+06$ & $3.6 \mathrm{E}+03$ & $1.3 \mathrm{E}+06$ & $5.3 \mathrm{E}+06$ \\
\hline
\end{tabular}

The total surface for 14 areas ranged from 13.8 hectares (ha) to 145.8 ha and between 4.1 to 11.1 ha for residential surface area.

The capacity of cabon sequestration and the level of carbon unsequestration for 14 residential building areas, grams/msq, during warm season for one day in Timisoara is shown in the figures 1 and 2 .

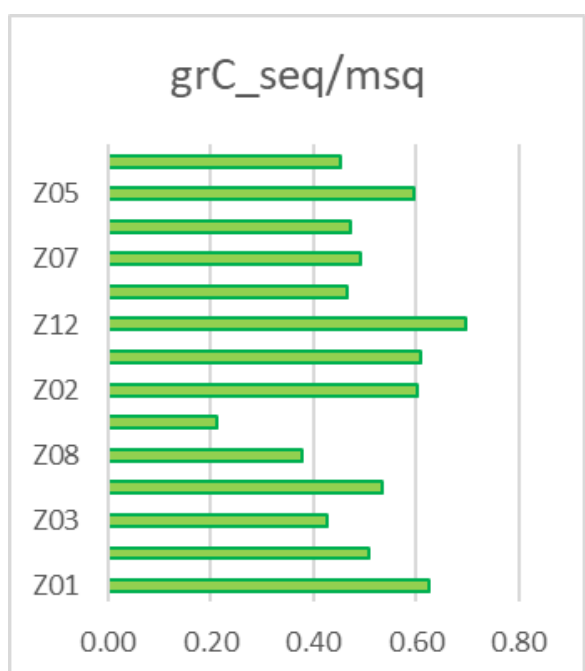

Fig. 1 Capacity of cabon sequestration for 14 residential building areas, grams/msq, Timisoara, 2016

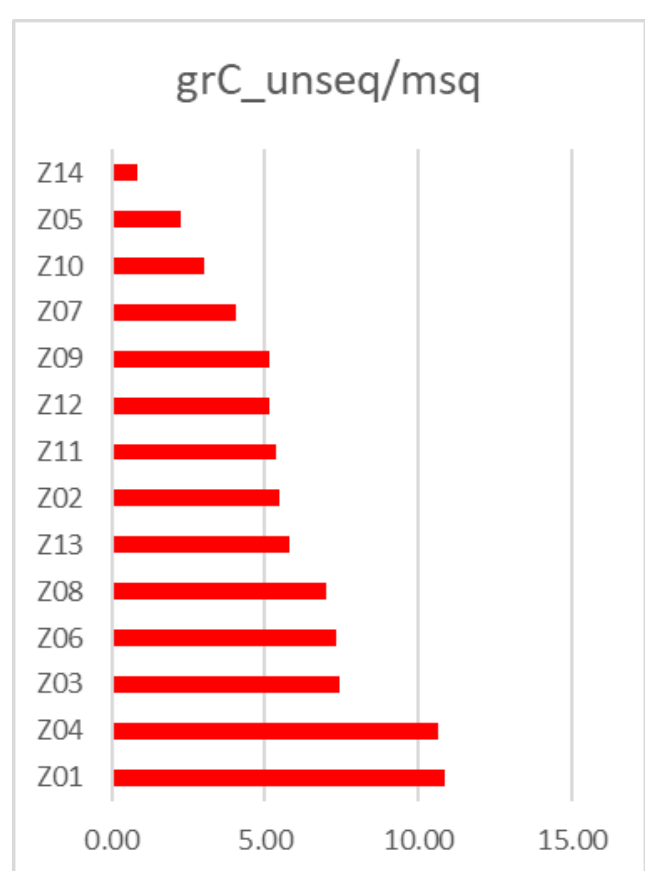

Fig. 1 The level of carbon unsequestration for14 residential building areas, grams/msq, Timisoara, 2016

The daily intensity of carbon sequestration in the warm season for 14 zones in Timisoaravaries between 0.21 0.70 grams per meter squared for residential areas. The amplitude is four times between minimum and maximum of capacity of carbon sequestration and by 15 times for the level of cabon unsequestration. The average ratio between unsequestration and sequestration of carbon is by 10 times.

\section{Discussions}

Before the last two centuries, mankind had lived without burning fossil fuel. The clean air depletion noticed by the gradual higher replacement of $\mathrm{O} 2$ with $\mathrm{CO} 2$ brought a challenge for mankind, simultaneously for the population, decision-makers and researchers. The periodic table's critical element highlighted in this research appears to be $\mathrm{O} 2$. O2 thereby joins and enlarges the group of other critical elements [21]. The output of $\mathrm{O} 2$ flows is directly linked with fossil fuel use, but it is more important for people survival. The integrated approach of $\mathrm{O} 2$ with EP is an analytical solution to have some right metrics.

For modeling the EO2P metrics with the developed flow-funds model, we considered to partially divide Timisoara into 14 zones using a conterminous spatial classification. Conterminous spatial areas and their segmentation have a strong analytical joint point, the exhausting of the classified urban surface of a city and the division of the whole city into the distinct and conterminous areas. We avoided the missing or overlapping of some urban micro zone-processes for the 14 zones. The 14 zones can be considered an experiment for the future TRU and for the new, ongoing TRU. Under these terms, we are observing and measuring to 
establish some solution to reduce urban pollution for every TRU to sustain the viable decisions.

In the research, the framework for balance construction was drafted by using the EO2P input and output flows. Within the developed model, the $\mathrm{O} 2$ production, as output flow for green micro-zones and $\mathrm{CO} 2$ output flows for building micro-zones, were measured. Input flows of fuel used for residential building micro-zones were indirectly recorded using $\mathrm{CO} 2$ output flows. In this way, it is possible to estimate the needed Trees fund and the benefits of urban forests [15]. We have modeled the $\mathrm{O} 2$ internal flows along with the $\mathrm{CO} 2$ polluting emissions that can be partially sequestered [2,13] for every zone. We now have a detailed assessment in each of the 14 urban areas for the residential EO2P process also for the two compound micro-zones. Our research reveals that the $\mathrm{O} 2$ production output flow for nano-zones will disappear within the aggregated process of the 14 zones. The $\mathrm{O} 2$ production is manufactured by chemical reaction inside of the Roegenian EO2P recipe.

The urban $\mathrm{O} 2$ production actually reduces urban pollution by 0.51 grams of carbon per squared meter for the whole residential building area noticed. At the moment, urban pollution [17] is not adequately diminished at national level with the $\mathrm{O} 2$ production recorded for the urban micro-processes. In databases [17], the pollution figures are in fact a gross aggregation for European countries, without containing the influence of urban $\mathrm{O} 2$ flows. A logical necessity results therefrom: to diminish the pollution figures in national, European and world databases using new $\mathrm{CO} 2$ and $\mathrm{O} 2$ metrics.

The built model allows recording and modeling of the $\mathrm{O} 2$ input flows and of the $\mathrm{CO} 2$ output boundaries flows. $\mathrm{CO} 2$ neutralized flows diminish the $\mathrm{CO} 2$ figures recorded in national database for urban areas and consequently include the $\mathrm{O} 2$ production. These $\mathrm{CO} 2-\mathrm{O} 2$ urban flows need to be properly integrated with the improving of methodologies $[16,17]$. At the city level, the flows for energy use and pollution in urban areas (cities) assures the build of urban $\mathrm{O} 2$ balances for every TRU or zone. The complete EO2P balances can be modeled based on the production of Tree/Graslland as Roegenian Fund and by measurement of $\mathrm{O} 2$ flows.

Urban planning requires the TRU segmentation for all conterminous land areas. We have assumed that segmentation of urban areas in Timisoara is considered under the spatial classification with analytical borders. In this case, the analytical spatial border between two conterminous and adjacent land areas was established by a vertical surface without the thickness dimension for every TRU-zone or any micro-zone. A close-up solution is found in some studies which consider the street as a canyon-process [19]. The flow modeling approaches the street-process with real boundaries. The flows on a street are measured using the height limit (19 and 39 meters) and considering the building walls as borders, in fact as analytical borders, only the external surface of walls. In other studies, the borders are not established and the flows are noticed inside of the process. The measurement in the center of the canyon [19] can be associated with an internal flow measured under the terms of the flow-funds model. In some studies, other characteristics are introduced. For some cities (London), the altitude and speed of the winds [22] have been estimated to ensure clean air transport and dispersion of indoor pollution.

The analytical spatial boundaries solve the issue of border-streets and offers the solution to include the border-streets areas into a TRU for the new ongoing GUP. In fact, until this solution is validated by a decision of the Local Council, the 109 border-streets could be considered, at present, as the complementary processes of at least two adjointed TRUs. For the residential building areas, the effects of EO2P flows for street areas, have no direct effects under the terms of the Roegenian flow-funds model. The EO2P flows for streets are noticed and recorded distinctively in other partial processes. Each street segment, considered as the nanozone, is assigned with a (postal) address and with grouped street numbers. The joining of micro-zones is accompanied by the aggregation of related EO2P flows. The solution in the flow-funds model is to measure only the boundary flows and to renounce (after the merge) to those that became internal, such as the production of the O2 internal flow for every Z1-Z14 - like zone resulting from the merge. The establishment of boundaries between the $\mathrm{HH}$ area and the adjacent streets, located in the same urban area, is precisely done at the delimitation of the properties through a vertical surface of a fixed height, thus without thickness. Both street and adjacent residential areas will always belong to the same microzone or TRU.

The trees inventory in Timisoara, with more than 35 tree features, [13] was used with the help of the inprocess measurement of $\mathrm{O} 2$ flows for street and $\mathrm{HH}$ areas. The inventory assures the calculation of benefits for $\mathrm{O} 2$ production as ecosystem services that generate the urban wellbeing [15].

The in-process measurement of EO2P flows solves the switching from the point-to-process analytical object and also from the recording of border flows [6]. The regular spot-focused measurement which records, for example, the pollutant airflow passing through the instrument [22] does not take into consideration what is happening in the rest of the 14 zones-processes. The pollution measurement is considered at the aggregated level of Timisoara using the in-process metrics with some stoichiometric figures [7]. We formulated the assertion that the results of these two measurements can be used alternatively or as a combination. It is the inprocess measurement that enables the transition from point-measurements to some analytically justified inprocess metrics. The reverse transition is more difficult in measurement. The research on some systematic inprocesses measurement of oxygen inputs and other basic materials at country level began over two decades ago [23]. In a recent research, the author proposes a OCO-2 state-of-the-art method for measuring $\mathrm{CO} 2$ in the stratosphere [24]. The measurement using the OCO-2 system can be considered on-spot (dispersed) according to the flow-funds model. These global measurements could provide the modeling of carbon sequestration capacity for some urban areas. These noticed and 
modeled metrics will be useful to compare with the pollution of the building using the in-process or on-spot tool. In the case of a city, the measurement can be satisfactorily approximated [24]. The lack of exact spatial analytical boundaries of the processes using OCO-2 system allows complementing other metrics. Lack of accurate spatial boundaries for macro urban processes, assessed by on spot figures, requires the return at the in-process metrics for the micro-areas with defined borders.

The spot-focused measurement is used for the main pollutants and some atmospheric characteristics according to national and European legislation. The results of some environmental measurements were resumed in the new GUP documentation by the evaluator. Subsequently, a separate report was made [25] for the correlation of urbanistic characteristics with the steady state population for the next decades according to the Eurostat projection, the increased E-P flows for every year, and the starting of heating island phenomena. For partially avoiding the negative effects of pollution, the need to use the in-process measurement for every TRU is the main result of the report assimilated by the public environment agency [20]. The consideration of a scientific point of view is stipulated in the Romanian Civil Procedure Code in the case of gaps (or inconsistencies) in the expertise. Thus, the Local Environmental Permit 1/2017 [20] formulates the condition to assess each TRU through the annual EO2P balances for the new ongoing GUP [9]. Consequently, the need to create a model framework for the elaboration of these balances has emerged. This was the main subject of the current research.

The EO2P metrics for urban areas need to be calibrated nationwide for each year. The figures for EO2P would therefore be different considering the data on annual energy use for previous years are sometimes remodeled at country level according to the express provision in the official statistical data computation procedure [16].

Detailed data of individual buildings, such as those available for London or Rotterdam, can be modeled in the coming years. A systematic research of the TRUs that will be established in the new GUP, by using the two EO2P measurements, in-process and on-spot, will be in position to ensure integration and a better, subsequent, modeling of the observed characteristics. The stoichiometric calculation in the present research has only considered $\mathrm{CO} 2$ without taking into account the $\mathrm{O} 2$ input flows for combustion of the heating-cooling devices. It is necessary to assess the water quantity of the photosynthesis process, also the vapor emission resulted from combustion and breathing, with respect to humans.

\section{Conclusions}

The solution for the spatial analytical boundaries of the two adjoining (back to back, not near) properties, located between two adjoining streets allows the modeling of continuously TRUs and the measurement of
EO2P flows at the boundary of these TRUs. This innovation, introduced for the first time in this research, has allowed modeling of EO2P boundary flows. The 14 zones in the city of Timisoara consist of 338 street as analytical nano-processes. Replacing the streetsboundaries with the analytical boundary for the 73 TRUs in place, the in force GUP has a solution. The solution is also valid for the building requirement of the EO2P balances for the new, ongoing GUP.

For the urban residential processes modeled in the present research, we have identified a workable solution in line with the local, national and European regulations for calculating integrated EO2P flows. The EO2P metrics allow us to build the balances in urban spaces delineated by spatial and temporal boundaries. The EO2P modelling revealed that the national energypollution figures did not integrate oxygen urban production which overestimates the reported figures for carbon dioxide pollutant.

This research has systematically observed and modeled 14 spatial conterminous processes for heating/cooling process of residential buildings (households). The processes were further segmented in two other partial processes: for EP and $\mathrm{O} 2$ production. During 2016, in the warm season, the daily carbon sequestration per meter squared is very low for all the 14 zones, save for Ghiroda Nouă, located outside (far from) the core city. The carbon sequestration ranges between 0.21 and 0.7 grams per meter squared, with an average level of 0.51 grams per meter squared. The O2 production ranges for the 14 green micro-zones between 0.002 tons and 0.13 tons every day in warm season. The $\mathrm{CO} 2$ pollution range between 0.09 and 2.66 tons every day and the average $\mathrm{CO} 2$ is by 14.9 times higher. The different sequestration carbon intensity justifies differentiated measures of public and private decision makers to reduce the pollution in residential areas.

The enjoyment of life is noticed in a small space, like the micro-zones noticed, where we are all living and working. It is the moment to understand that the future of humans inside urban processes depends on how they will manage the mutually beneficial integration of artificial land areas and natural land areas. The future (slow or quick) de-urbanization, extreme phenomena such as storms, heat islands and waves are hypotheses introduced into modeling by climate scientists along with the records about the on-site partial sequestration of carbon and other pollutants.

\section{Nomenclature}

\section{Acronyms}

$\begin{array}{ll}\mathrm{E} & \text { Energy (use) } \\ \mathrm{O} 2 & \text { Oxigen (production) } \\ \mathrm{P}(\mathrm{CO} 2) & \text { Pollution (carbon dioxide) } \\ \mathrm{EO} 2 \mathrm{P} & \text { Energy-Oxigen production- } \\ & \text { Pollution (process or flow) } \\ \mathrm{HH} & \text { Household(s) } \\ \mathrm{msq} . & \text { Meter squared }\end{array}$




\begin{tabular}{|c|c|}
\hline GUP & General Urban/istic Plan \\
\hline NUTS3 & Nomenclature of Territorial \\
\hline (424) & $\begin{array}{l}\text { Units, level three, code of } \\
\text { units }\end{array}$ \\
\hline TRU & Territorial Reference Unit \\
\hline $\mathrm{CO} 2$ & Carbon dioxide \\
\hline $\mathrm{pRP}$ & partial Roegenian Process \\
\hline LAI & Leaf area index, msq \\
\hline LAD & Leafa rea density, $\mathrm{cm}$ \\
\hline & Cube meter \\
\hline \multicolumn{2}{|l|}{$\begin{array}{l}\text { Found in } \\
\text { References }\end{array}$} \\
\hline PMT & $\begin{array}{l}\text { Primaria Municipiului (City } \\
\text { Hall) Timisoara }\end{array}$ \\
\hline RNAEP & $\begin{array}{l}\text { Romanian National Agency } \\
\text { for Environment Protection }\end{array}$ \\
\hline CLRTAP & $\begin{array}{l}\text { CONVENTION ON LONG- } \\
\text { RANGE }\end{array}$ \\
\hline & $\begin{array}{l}\text { TRANSBOUNDARY AIR } \\
\text { POLLUTION }\end{array}$ \\
\hline EW-MFA & $\begin{array}{l}\text { Economy-wide material } \\
\text { flow accounts }\end{array}$ \\
\hline PMT & $\begin{array}{l}\text { Primaria Municipiului (City } \\
\text { Hall) Timisoara }\end{array}$ \\
\hline
\end{tabular}

\section{Symbols}

$\mathrm{i}$ - zone $1, \ldots, 14$

$\mathrm{j}-$ street $1, \ldots . ., 338$

$\mathrm{k}$ - street segment $1,2, \ldots$ for street $\mathrm{j}$

$\mathrm{ijk}$ - (proces or characteristic assigned for) street segment $k$, street $j$ and zone $i$

$C s a_{\mathrm{jk}}-$ coefficient of spatial allocation of people for street segment $k$, street $j$

enuse $H H / m s q$ - energy use (gas) daily per capita, $\mathrm{kWh} /$ capita

$E m_{1}$ - consumption expenditure per $\mathrm{HH}$ and month 1, lei

$E_{\mathrm{i}}$ - Energy use for residential building/HH per day

fco $2 \mathrm{HH}-\mathrm{CO} 2$ emission factor for building $(\mathrm{HH}), \mathrm{kg}$ $\mathrm{CO} 2 /$ toe $(0.324)$

$L s_{\mathrm{ij}}$ - length of street $\mathrm{j}$, zone $\mathrm{i}$

$L s s_{\mathrm{ijk}}$ - length street segment $\mathrm{k}$, street $\mathrm{j}$, zone $\mathrm{i}$

$l$ - number of months per warm season (6)

$N p s_{\mathrm{ij}}$ - postal address numbers for street $\mathrm{j}$, zone $\mathrm{i}$

$N p s s_{\mathrm{ijk}}-$ postal address numbers for street segment k, street $\mathrm{j}$, zone $\mathrm{i}$

NpuHH - number of people per HH in urban area

$N d w s$ - number of days per warm season in Timisoara

(150)

$p k W h$ - energy price per $\mathrm{kWh}$, lei $/ \mathrm{kWh}$

$P_{\mathrm{ijk}}$ - the people with residence on street $\mathrm{j}$ and street segment $\mathrm{k}$ and zone $\mathrm{i}(1, \ldots, 14)$;

$\mathrm{PrO}_{2} \mathrm{HH}_{\mathrm{i}}-\mathrm{O} 2$ production for one day inside of the green micro-zone i (non artificial land area)

pO2 - productivity of $\mathrm{O} 2$ (unit production) per year

(warm season for trees), $\mathrm{kg} \mathrm{O} 2 / \mathrm{msq}(0.1)$

$\mathrm{RAD}$ - the second-order radical (mathematics)

$S L A I t$ - surface LAI for trees, meter squared

$S L A I g$ - surface LAI for grassland, meter squared

\section{References}

1. Latham J et all, FAO Global Land Cover (GLCSHARE) Beta-Release 1.0 Database, Land and Water Division, FAO, Rome, (2014)

2. Nowak D., et all, Arboriculture \& Urban Forestry, 33(3):220-226 (2007)

3. Nowak D. et all, Environmental Pollution, 1978, 229-236, (2013)

4. Nowak D. et all, Environmental Pollution, 193 119-129, (2014)

5. Hutyra, L.R. et all, Global Change Biology 17, 783-797, doi: $10.1111 / \mathrm{j} .1365-$ 2486.2010.02238.x, (2011)

6. Georgescu-Roegen N. The Entropy Law and the Economic Process, Harvard University Press, Cambridge, Massachusetts, (1971)

7. PMT, Action Plan for Sustainable Energy (in Romanian), Timisoara (2014).

8. Mahzouni A., Journal of Cleaner Production, 1095, 1476-1486 ()2017

9. PMT, New General Urban Plan, 2010-2016, https://www.primariatm.ro/index.php?meniuId= $2 \& \mathrm{lg}=$ ro\&viewCat $=3257$, (2016).

10. Bringezu, S., Resources 4, no. 1: 25-54 (2015)

11. Radoslav R., Coloquium Politicum, 2(4) JulyDecember $2011 \quad$ (In Romanian) http://www.bcut.ro/dyn_doc/revista/colpol4.site /colpol4.p29-46.Radoslav.pdf, (2011)

12. PMT, General Urban Plan of Timisoara, https://www.primariatm.ro, (2002)

13. Ciupa V et al, Timisoara Verde. The green space system for Timisoara (in Romanian), Publishing House Marineasa, Timisoara (2005)

14. Janjäll S, Atmospheric Environment, https://doi.org/10.1016/J.ATMOSENV.2015.01 .052 (2015)

15. Endreny, T. et all, Ecollogical Modelling, 360, 328-335

https://doi.org/10.1016/J.ECOLMODEL.2017.0 7.016

16. Eurostat,, EW-MFA Manual 2016, Draft version on DPO, Annex to EW-MFA Manual 2015 (2016)

17. UNECE, https://www.unece.org/fileadmin/DAM/env/lrta p/full\%20text/1979.CLRTAP.e.pdf, 1979 CLRTAP, New York, (2018)

18. Lenhart J., van Vliet B., Mol. A. P.J., Journal of Cleaner Production, 107, 593-601 (2015)

19. Lietzke B, Vogt R., , Atmospheric Environment, 74 (2013), 60-72, (2013)

20. RNAEP, Local Environmental Permit no. 1/2017 for General Urban Plan of Timisoara, (2017) 
21. Graedel T. E. et all, $\mathrm{H}$ Proceedings of the National Academy of Sciences April 2015, 112 (14) 4257-

4262; DOI:10.1073/pnas.1500415112, (2015)

22. Drew D. R. et all Journal of Wind Engineering and Industrial Aerodynamics, 121, 98-105, , https://doi.org/10.1016/j.jweia.2013.07.019, (2013)

23. RNAEP database, 2018.

24. Matthews Emily et all, The Weight of Nations, World Resources Institute, Washington DC, (2000)

25. Hakkarainen, J. et all, Geophys. Res. Lett., 43, 11,400-11,406, doi:10.1002/2016GL070885, (2016)

26. RNAEP, Report no. 2932 / 29.11.2016 (in Romanian/ro), (2016) 